\title{
Research on the Training of On-the-job Graduate Students in Armed Police Forces
}

\author{
Zou Li, Cao Yu, Xiao Pengcheng \\ Logistics University of PAP
}

\begin{abstract}
As a representation of the high-level talents of the armed forces, the graduates of the armed police academies and universities will become an important force in the future of our army's modernization construction. This paper takes the inservice postgraduate as the research object, analyzes the current status of the postgraduate training mode of the Armed Police Force Academy and then summarizes the problems in the university, for example, the practical ability training in the inductive colleges is ignored, the "double tutor system" is not fully implemented, the management and institutional constraints are not strict and the political and ideological work is difficult. The paper also summarizes predicaments of students, such as the professional course results are not ideal and the coordination between study and working hours is difficult. Finally, the paper gives corresponding suggestions on the improvement of on-thejob training mode in armed police colleges.
\end{abstract}

Keywords-Armed police academies; In-service graduate students; Training

\section{INTRODUCTION}

As a representative of the high-level talents of the armed forces, the graduates of the armed police academies will become an important force in the future of our army's modernization construction. The cultivation of the efficiency is related to the construction of high-quality talents for our military. Over the years, under the inspiration of relevant policy measures and missions, the quality of the training of postgraduate students in armed police academies has been continuously improved. Under the background of national defense and military reform, taking the opportunity of the military academies and universities to carry out in-depth discussion on the new era of running schools, the in-depth study of the problems existing in the postgraduate training model of the armed police academies is conducive to promoting the reform and innovation of academies and universities. The level of education and education provides a strong talent and governance support for the realization of the Chinese dream of strengthening the military dream.

Military Theory Research Project of Logistics University of PAP: Discussion on the Training Mode of Military College Students' Learning Ability Based on Ubiquitous Learning

Contract No:WHL201742.

\section{RESEARCH BACKGROUND}

\section{A. Transformation of postgraduate training structure in armed police academies}

In recent years, the Armed Police Academies has attached great importance to the training of professional degree masters, and the proportion of graduate students in professional degrees has increased continuously, from $50 \%$ to $60 \%$ in 2017 . The source structure has been continuously optimized, and the growth officers of the school are strictly controlled. Graduate students greatly reduced the enrollment ratio of fresh graduates and expanded the enrollment ratio of serving cadres. From these changes, it is easy to see that the party and the state attach great importance to the issue of on-the-job postgraduate training, and the level of education has developed rapidly.

\section{B. Reform of in-service postgraduate training methods in armed police academies}

In recent years, the postgraduate training mode of military academies has been continuously reformed. On the one hand, the armed police academies and scientific research institutions have been jointly trained to coordinate the establishment. The academies have taken the lead in improving the joint training system mechanisms and safeguard measures, undertaking the curriculum teaching tasks. The institutions make charge of the research guidance tasks. On the other hand, advance the fusion culture [1]. The in-service cadres who participated in the training of middle and senior commanders completed the course study in the academies and universities, completed the research in the military positions, and implemented the joint training mode of dual tutors.

\section{Insufficient attention paid to the postgraduate training of the armed police academies}

The in-service postgraduate students of the armed police academies have effectively supplemented the high-level talent team of the troops. Through field research and discussions with a number of in-service graduate students, we found that there is some controversy about the cognition of in-service postgraduate students. At present, the benefits of in-service graduate students trained by armed police academies are quite different, and there are many problems that need to be solved urgently. Many academies and universities are concerned about the number of enrollment and graduation rate. They lack the thinking about whether the in-service postgraduate 
education is suitable for the troops and cause certain losses to the educational resources.

\section{EXISTING PROBLEMS}

\section{A. Problems in the academies}

1) Focus on theoretical training, ignore the cultivation of practical ability

For a long time, the training of in-service graduate students in military academies often only focuses on the cultivation of theoretical research ability and neglects the cultivation of practical ability. Because the in-service postgraduate education is set in China for a short period of time, the training model is still not perfect and there is no unified standard training mechanism. Most postgraduate training units are basically consistent with the full-time graduate students in the in-service postgraduate training model. Whether in curriculum setting, curriculum implementation or in the research of dissertations, the postgraduate training units are still based on theoretical research. The teaching mode is also based on theoretical lectures and the practice time is little, failing to fully reflect the practicality, technicality and practicality of the in-service graduate education of armed police academies [2]. The characteristics have led to the lack of pertinence in the training of military personnel and the lack of military vocational education to cultivate characteristics.

\section{2) "Double tutor system" is not in place}

The essential difference between graduate students and undergraduates is that the postgraduate training adopts the tutor system. The "double tutor system" is adopted for the inservice postgraduate training. Academic tutors impart theoretical knowledge, and military tutors develop the practical skills of graduate students. However, the current implementation of the "double tutor system" is not in place. The in-service graduate students are only instructors in the academies and universities, and there is no guidance from the military instructors. This leads to the solid theoretical knowledge of professional degree graduates, but the practical ability is poor and cannot be used. Theoretical knowledge solves practical problems and does not meet the goal of professional degree graduate training.

\section{3) Management and institutional constraints}

The training unit intentionally or unconsciously relaxes the management and institutional constraints on the in-service graduate students and artificially influences the quality of the in-service graduate students. Since most of the in-service graduate students have certain social status and influence, they belong to the category of "senior and excellent learning". They have various complicated relationships with schools, teachers, managers. Teachers, administrators, and even school leaders clearly know that these graduate students cannot meet the requirements of the school in terms of course study and assessment and the work of the thesis. Some of the learning links are not fully in place, but because of the face, they look at each other and hold the attitude of not being embarrassed. They intentionally or unconsciously relax their management and quality requirements [3].

\section{4) Political and ideological work is difficult}

The day-to-day management and political and ideological work of in-service postgraduates are difficult and they cannot be touched by the school's political and ideological work and daily management. Since most of the in-service graduate students live in the workplace, many people come to the school to listen to the rush of classes. During the graduation thesis, there is no news. In addition to attending several ceremonies, it is rare to show up at the school. Therefore, it is difficult for the management department to centrally manage the in-service graduate students. It is even difficult to convene a postgraduate plenary session and to organize political studies for all graduate students. During their departure from school, it is difficult to convey the spirit of some notices, announcements and training management documents to everyone. It is difficult for each graduate management team to organize a merit evaluation for all graduate students. Even some full-time in-service graduate students must call the management of the unit at the beginning of each semester.

\section{B. Problems in the students}

\section{1) Professional courses are less complete}

Class attendance is low and the quality of course learning is not guaranteed. The vast majority of in-service graduate students complete their studies in the form of entering the school without leaving their posts. After the admission, their work has hardly been alleviated, the study time is relatively scattered, and they are unable to get on time due to work in the course of the course. Their time and energy of the course are not guaranteed. In particular, part-time in-service graduate students are required to concentrate on 6-month course faceto-face during their degree studies. However, some in-service students still miss many opportunities for face-to-face teaching due to work needs, resulting in higher classroom absenteeism during face-to-face teaching. . This makes the in-service postgraduate course study lack systematic. It is difficult for the in-service postgraduate students in the natural sciences to fully participate in the training of the course experiment. The latest test technology cannot be mastered well, and the quality of the course study is difficult to guarantee. In addition, some inservice graduate students rarely attend classes, but require teachers to give them the opportunity to take the exams, and even the teachers do pre-test counseling.

\section{2) Learning and working time coordination difficulties}

The working conditions and working hours of the dissertation are not fully guaranteed. It is difficult to guarantee the quality of the thesis. Some in-service graduate students have to return to their original units to complete their dissertation because of their work needs. It is difficult for teaching and research institutions to provide graduate students with high-quality, high-quality master's or doctoral thesis. In order to ensure the completion of the thesis, some in-service graduate students must also take into account the completion of the unit's work tasks. Only the unit and the school run at both ends, and the paper research work is intermittently carried out. It is inevitable that the paper work will be lost. The paper work lacks continuity and the quality of the paper is difficult to guarantee. What's more, some Ph.D. thesis research is completed by master students. Some non-full-time graduate 
thesis work should be completed by the instructor. [4]Finally, the test results and written papers of others are used to defend and falsify, resulting in extremely bad. social influence.

\section{POLICY RECOMMENDATIONS}

\section{A. Improvement measures at the institutional level}

1) Update teaching mode, focus on practical ability training

First, optimize the informationization of teaching content. On-the-job postgraduate education must break through the traditional teaching model centered on the academic system, and open up a new teaching model with problems as traction, practical ability as the focus, and practice training as the leading. Actively adopt practical methods such as war cases and homework assignments, extend classrooms from academies to military positions, and make full use of inservice training courses to implement integrated talent training. Second, reform teaching methods. The particularity of on-thejob postgraduate teaching requirements determines that the postgraduate teaching method should fully embody the principle of unification of teaching and application. In view of the training objectives of in-service graduate students, the teaching methods of teaching students in accordance with their aptitude will be established, so that graduate students can be fully developed. The following teaching methods can be adopted for on-the-job postgraduate teaching.

\section{2) Optimize the construction of the mentor team}

When selecting and hiring in-service postgraduate tutors, institutions not only pay attention to their ability to guide students to study and research, but also to pay attention to their practical experience. Although the tutors of academies and universities pay attention to the transfer of theoretical knowledge, they must also have certain military practical experience. Otherwise, the actual teaching will not meet the teaching requirements. Institutions should regularly organize academy tutors to participate in actual drills or substitute exercises, and increase the practical experience of the troops so that the theory and practice can be better combined in the classroom. In addition, establish a relatively complete supervisory management system, and organize the instructors to conduct regular academic meetings to master the research progress and progress of the students. In addition, a mentoring guidebook should be established to clarify the respective duties and responsibilities of the instructor and the army instructor. This not only supervises the guidance of the tutor to the trainees, but also strengthens the communication and communication between the trainees and the tutors. Thus form a harmonious relationship between teachers and students, improve the creativity and practical ability of the trainees while improving the quality of teaching and research.

3) School leaders, class teachers, and tutors must correct their schooling ideas

The first is to correctly handle the relationship between the use of intangible resources of on-the-job graduate students and the quality of on-the-job postgraduate training. Schools must respect the social status of in-service graduate students and impose strict requirements on them. They cannot exchange their quality of training in exchange for certain aspects of school development. The second is to correctly handle the relationship between the overall quality of graduate students and the quality of on-the-job postgraduate training. The quality requirements for postgraduate education in the school can only be one level. The gold content of the same diploma in the same school should be the same. It is not allowed to set different quality standards because of "out of production" or "on-the-job". It cannot affect the postgraduate education of the school because of the quality of the in-service graduate students. The overall reputation of the school, from the height of the seriousness and comparability of the maintenance of the diploma, from the height of achieving graduate education and sustainable development of talent training, seriously consider the quality of in-service postgraduate training to maintain the good reputation of postgraduate education.

\section{B. Improvement measures at the student level}

1) Strengthen the education of the "student" consciousness of on-the-job graduate students

When in-service graduate students enter the school, even when applying for the exam, managers and tutors should strengthen their "student" awareness education and require them to always follow the principle of "student's vocation is learning". In particular, for on-the-job postgraduate students in ordinary full-time postgraduate students, they should be strictly required to adjust their mentality as soon as possible after entering the school, to position themselves, to strictly meet their own management standards and learn standards, to focus on their studies and to arrange them properly. The work during the reading period is to minimize the work pressure during the reading period and to ensure that the necessary time and energy are invested.

2) Strengthen the quality management of the on-the-job postgraduate training process

The training objectives of in-service graduate students must be achieved through strict process management. Without a solid education and teaching process and the management of the paper work process, the realization of the goal will become a castle in the air. In the process of in-service postgraduate training, we should focus on the following four links: First, the instructor will carefully check the admissions interview. During the interview, the instructor should try to enroll those online in-service candidates who can guarantee the time and effort of the study, and instruct them to submit the agreement or guarantee signed by the unit leader before the school entrance to reduce the workload during their study. [5]Second, take effective measures to effectively improve the rate of attendance especially for part-time graduate students. Team cadres and academic staff should frequently go to the classroom to do on-the-job postgraduate class attendance work The class teachers should strictly attend class attendance and calculate the usual grades according to the rate. Third, implement a regular meeting and regular meeting system for tutors. The tutor should hold regular graduate conferences and instruct the graduate students to regularly report on the course study and thesis work. No matter where the paper research work is done, it is necessary to return to the school to do a mid-term report during the work of the paper. Fourth, the 
training link must not relax the quality requirements of certain links or the deadlines of certain business materials.

3) Strengthen the mid-term assessment and the quality evaluation of the on-the-job postgraduate students

In order to encourage in-service graduate students to invest time and energy in learning, those who fail to pass the midterm assessment should be resolutely eliminated or postponed; in addition, the quality of the dissertation should be strictly reviewed. First, the school should randomly select a part of the on-the-job postgraduate thesis to be sent to the off-campus peers for blind review and those who fail to pass the blind trial will not be allowed to defend the thesis. Secondly, in order to prevent the thesis defense committee from going through the game, before the school degree evaluation committee can verify the degree, the old experts of the teaching supervision group will be sampled and re-examined by the on-the-job graduate thesis, and the quality requirements of the corresponding thesis will not be met. [6]The list is not included in the list of the degree approved by the school's degree assessment committee. Third, the training unit should establish a quality reporting system for on-the-job postgraduate degree awards, and us the supervision function of the masses to prevent individual in-service graduate students from "using the power or money to ask people to make papers in exchange for diplomas".

4) Relieve the contradiction between engineering and graduate students

First, implement the credit system and flexible academic system. The minimum credit requirements for the corresponding degree shall be specified, and the training period of the in-service postgraduate students shall be extended appropriately. The maximum length of study period may be extended to 5-6 years to ensure that the accumulated time for postgraduate study is 3 years before applying for a degree. Second, improve teaching methods, teaching content and teaching methods. In view of the characteristics of on-thejob postgraduates, it is appropriate to reduce the number of inservice postgraduate courses, strengthen the self-study tutoring of theoretical courses, and ensure the completion of the experimental teaching. Finally, practice free time teaching. For full-time doctoral students with a higher proportion of full-time students and all part-time graduate students, the school should try to select the most leisurely seasons or time periods for the majority of students according to their specific work, such as face-to-face teaching, Open weekend courses, "May 1" and "National Day" long vacation courses, evening classes, etc. Emphasis is placed on assessing students' ability to integrate knowledge, using the theory and techniques they have learned to solve the actual problems of the military, and avoiding excessively memorable questions.

\section{CONCLUSION}

This paper analyzes the current situation of the in-service postgraduate training mode of the armed police colleges, and combines the background of the reform of the military academy and the characteristics of the in-service postgraduate students. This paper takes the in-service postgraduate as the research object, analyzes the current status of the postgraduate training mode of the Armed Police Force Academy and then summarizes the problems of academy, such as the neglect of practical ability training in the inductive colleges, the implementation of the "double tutor system" is not in place, the management and institutional constraints are relaxed and the political and ideological work is difficult. The paper also summarizes problems of students, such as the low degree of completion of professional courses and the difficulty of coordination between study and working hours. In view of the existing problems, it is pointed out that in the education of colleges, it is necessary to improve the teaching methods and optimize the construction of tutors, correct the idea of running a school and adopt a dual management model. Students should strengthen the education of "student" awareness, strengthen the quality management of in-service postgraduate training, use the mid-term assessment diversion, consider the quality evaluation of the papers and alleviate the contradictions in the work and study. The paper has proved the important significance of the development of the postgraduate education mode in the new era, has constructed the training mode of "combination of warfare and study" to make graduate education closer to the army and closer to the future battlefield.

\section{REFERENCES}

[1] Zhou Wenhui, Cao Zhenqi. New Situation, Problems and Countermeasures of Part-time Graduate Enrollment[J]. China Higher Education Research, 2018(01): 81-86. (In Chinese)

[2] Dai Zhiyong. Reflections on the Management of Part-time Graduate Students in Academies and Universities under the New Situation[J]. Academic Journal, 2018(21): 13-14. (In Chinese)

[3] Gao Xinbao, Yuan Xichao, Wang Jinzhu. Analysis of the characteristics of graduate student source structure and its training methods [J]. Science and Technology Journal (first issue), 2018 (05): 35-36. (In Chinese)

[4] Dan Zeng Zhuoma. Investigation on the status of postgraduate training in Tibet Party School [D]. Tibet University, 2017. (In Chinese)

[5] Zhao Xiaofeng, Li Hongcai, Zhong Qiyuan, Hou Chuanxun. Exploration and Practice of On-the-job Postgraduate Education Based on Innovative Thinking [J]. Continuing Education, 2017, 31(01): 54-56. (In Chinese)

[6] Pan Zhengqiang, Feng Jing. Reflections on the Cultivation of Postgraduate Ability in Military Schools[J]. Education and Teaching Forum, 2015(09): 180-181. (In Chinese) 